\title{
PERFORMANCE INDICATORS BASED ON COLLABORATION BENEFITS
}

\author{
Luis M. Camarinha-Matos, António Abreu \\ New University of Lisbon \\ Quinta da Torre-2829 Monte Caparica, PORTUGAL \\ cam@uninova.pt.aifa@fct.unl.pt
}

\begin{abstract}
The identification and characterization of collaboration benefits is an important element for the wide adoption of the collaborative networks paradigm. This paper introduces an approach for the analysis of benefits in collaborative processes for networks of enterprises. The potential application of some indicators derived from this analysis is also discussed in the VO breeding environment context.
\end{abstract}

\section{INTRODUCTION}

The participation in a collaborative network of enterprises is commonly assumed to bring valuable benefits to the involved entities. These benefits include an increase of the "survival capability" in a context of market turbulence, but also the possibility to better achieve common goals. On the basis of these expectations are, among others, the following factors: sharing of risks and resources, joining of complementary skills and capacities, acquisition of a (virtual) higher dimension, access to new / wider markets and new knowledge, etc.

But it is also easily recognizable that collaboration introduces high overheads due to the higher coordination costs, diversity of working methods and corporate culture, which induces higher transaction costs, loser control structures, etc.

Is the balance between the potential benefits and the increased overheads substantially positive? Literature in the field, as well as a growing number of practical case studies, seems to indicate that the answer is yes. It is however difficult to prove. It is difficult to find some objective indicators in order to show to a SME that there are potential benefits in joining a collaborative network.

In order to address this problem, the issue of performance measurement and benefit analysis in collaborative networks started to attract attention. Being able to measure the performance of a collaborative network as a whole, as well as the performance of each of its singular members, could represent an important boosting element for the wide acceptance of the paradigm. However performance indicators tailored to collaborative networks or even an adequate conceptual basis for benefit analysis are not available yet [7].

Performance measurement depends on the premises of the measurement system used. Collaborative networks challenge the premises of the methods developed in 
the past, therefore the applicability of existing measurement systems in this area is questionable. This paper contributes to establish a basis for the analysis of benefits in collaborative networks, suggests some indicators, and discusses their measurability.

As a basis for this work inspiration is sought in the areas of social actor networks [12], transactions cost theory [13], and game theory [1,9]. Of particular relevance are the developments in graph theory tailored to social networks analysis, which have introduced a number of concepts such as prominence of actors in a network, members' centrality, prestige, etc, and approaches to measure / compute them [3]. Although these approaches are, in many publications, quite abstract, lacking some economic and practical focus, they be used as a source of inspiration to analyze collaborative networks of enterprises.

Other recent works have attempted to develop benchmarks for collaborative networks $[8,11]$, although the limited data available is a major obstacle. In [10] (is discussed) an approach to develop a predictive performance indicators for VO.

The approach followed in this paper assumes the existence of a $V O$ breeding environment (VBE) as a pre-condition for the effective establishment of dynamic virtual organizations (VO) [5], [6]. A VBE represents an association or pool of organizations and their related supporting institutions that have both the potential and the will to cooperate with each other through the establishment of a "base" longterm cooperation agreement. When a business opportunity is identified by one member (acting as a broker), a subset of these organizations can be selected and thus forming a VO. Various VOs can coexist at the same time in the context of a VBE. A breeding environment, being a long-term networked structure, presents the adequate base environment for the establishment of cooperation agreements, common infrastructures, common ontologies, and mutual trust, which are the necessary facilitating elements when building a new VO. In other words, a VBE represents a group of organizational entities that have developed a preparedness for cooperation, in case a specific opportunity arises. Industry clusters or industry districts are examples of such breeding environments.

The existence of this long-term environment can also provide the basis to record performance data about past collaboration occurrences, a source for computation of performance indicators. In this context, the definition of a cooperation benefits model and application of a set of indicators can be a useful instrument to the VBE manager, to a VO broker, and also to VBE members.

\section{BENEFITS CONCEPT}

The actual meaning of a benefit depends on the underlying value system that is used in each context. In order to illustrate this concept let us consider the following two examples:

\section{Example 1-Logistics area}

Four transportation companies (E1, E2, E3, E4), as illustrated in Fig.1, have received, each one, an order from their respective customers (i.e. C1, C2, C3, C4). Each order requests 8 containers, while each transportation company has the capacity of delivering 1 container per day. The maximum delivery date for each order is, respectively, $8,2,12$, and 4 days from now. 


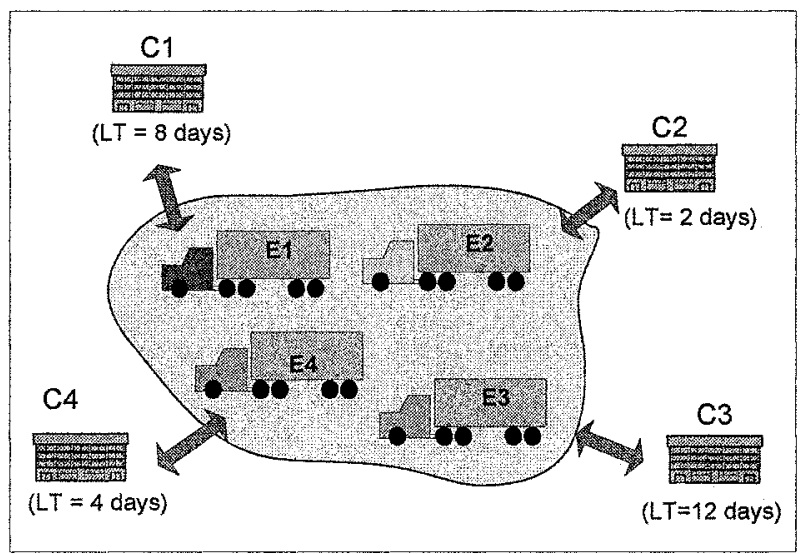

Figure 1 - Cooperation in transportation

In this case, without any cooperation agreement, only E1 and E3 have the capacity to satisfy their orders in time.

However, if the 4 enterprises decide to collaborate all orders can be delivered in time, as shown in Fig. 2.

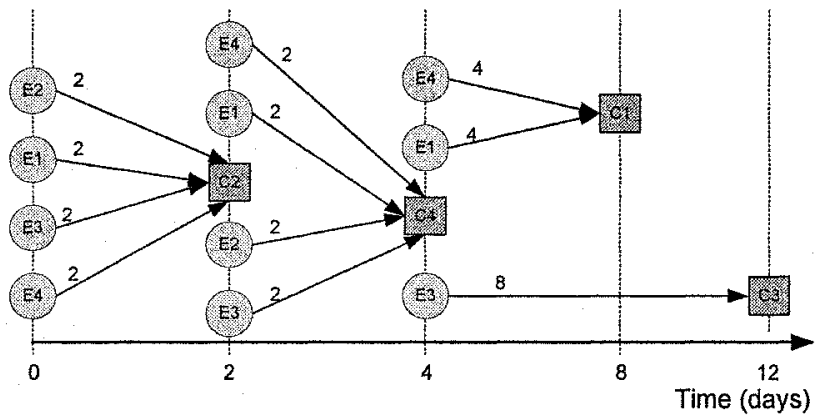

Figure 2 - Transportation collaboration over the time

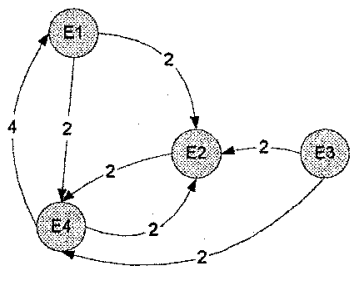

Figure 3 - Benefits exchanged among partners

In this case, enterprise E2 is the first one to receive help from the others as it has the smallest lead time and the next one is E4. After helping E2 and E4, E1 can no longer satisfy its order in time and also needs help. E3 can still fulfil its order even after helping the others. In this example, the value system consists only of one variable that is the quantity of containers, and the cooperation benefit is represented by the number of containers that one partner transports on behalf of another. Fig. 3 shows the exchange of benefits among partners for this case. A direct link represents benefits received by one enterprise form another enterprise. 


\section{Example 2 - Joint purchases}

Three small enterprises in a given sector realize that one big competitor buys components from the same supplier at a much cheaper price as the supplier offers quantity discounts as shown in Fig. 4. Therefore, the three enterprises decide to establish a cooperation agreement in order to make joint purchases and thus getting higher quantity discounts. Fig. 5 shows the costs in case of individual and joint purchases. Fig. 6 shows, for each cooperative scenario, the total amount of money that can be saved, i.e. cooperation benefit value $V$, when embarking in a collaborative process. In this example, the collaboration benefit is represented by the amount of money that is saved when partners purchase in group.

\begin{tabular}{|c|c|}
\hline Number of & Trit Pree \\
\hline jorts & $($ ) \\
\hline 1500 & 35 \\
\hline 2000 & 30 \\
\hline 2500 & 29 \\
\hline 3000 & 28 \\
\hline 3500 & 27 \\
\hline 4000 & 26 \\
\hline 4500 & 25 \\
\hline 5000 & 24 \\
\hline 5500 & 23 \\
\hline 6000 & 22 \\
\hline 6500 & 21 \\
\hline 7000 & 20 \\
\hline
\end{tabular}

Figure 4 - Price of parts

\begin{tabular}{|c|c|c|c|}
\hline Scenario & Number of parts & Umit Price (6) & Total price $\mathrm{C}-\mathrm{C}$ \\
\hline $\mathrm{E} 1$ & 1500 & 35 & 52500 \\
\hline E2 & 2000 & 30 & 60000 \\
\hline E3 & 3500 & 27 & 94500 \\
\hline $\mathrm{E} 1+\mathrm{E} 2$ & 3500 & 27 & 94500 \\
\hline $\mathrm{E} 1+\mathrm{E} 3$ & 5000 & 24 & 120000 \\
\hline$E 2+E 3$ & 5500 & 23 & 126500 \\
\hline $\mathrm{E} 1+\mathrm{E} 2+\mathrm{E} 3$ & 7000 & 20 & 140000 \\
\hline
\end{tabular}

Figure 5 - Total price for each scenario

\begin{tabular}{|c|c|}
\hline scenarlo & Cooperation Beiefit Value $(6)$ \\
\hline E1 & $V\left(E_{1}\right)=0$ \\
\hline E2 & $V\left(E_{2}\right)=0$ \\
\hline E3 & $V\left(E_{3}\right)=0$ \\
\hline $\mathrm{E} 1+\mathrm{E} 2$ & $V\left(E_{1} \cup E_{2}\right)=C\left(E_{1}\right)+C\left(E_{2}\right)-C\left(E_{1} \cup E_{2}\right)=18000$ \\
\hline $\mathrm{EI}+\mathrm{E} 3$ & $V\left(E_{1} \cup E_{3}\right)=C\left(E_{1}\right)+C\left(E_{3}\right)-C\left(E_{1} \cup E_{3}\right)=27000$ \\
\hline $\mathrm{E} 2+\mathrm{E} 3$ & $V\left(E_{2} \cup E_{3}\right)=C\left(E_{2}\right)+C\left(E_{3}\right)-C\left(E_{2} \cup E_{3}\right)=28000$ \\
\hline $\mathrm{E} 1+\mathrm{E} 2+\mathrm{E} 3$ & $V\left(E_{1} \cup E_{2} \cup E_{3}\right)=C\left(E_{1}\right)+C\left(E_{2}\right)+C\left(E_{3}\right)-C\left(E_{1} \cup E_{2} \cup E_{3}\right)=67000$ \\
\hline
\end{tabular}

Figure 6 - Amount of saved money

Please note that the purpose of these examples was only to illustrate the concept of benefit and therefore a number of simplified assumptions were made.

In general the concept of benefit for the context of networks of enterprises most likely represents a measure of the economic benefits (in the sense of net profit), while in the context of a NGO it could represent a more abstract notion of acquired social prestige or peer recognition. Nevertheless, in most cases this concept could be expressed as a combination of multiple variables, as illustrated in Fig. 7. 


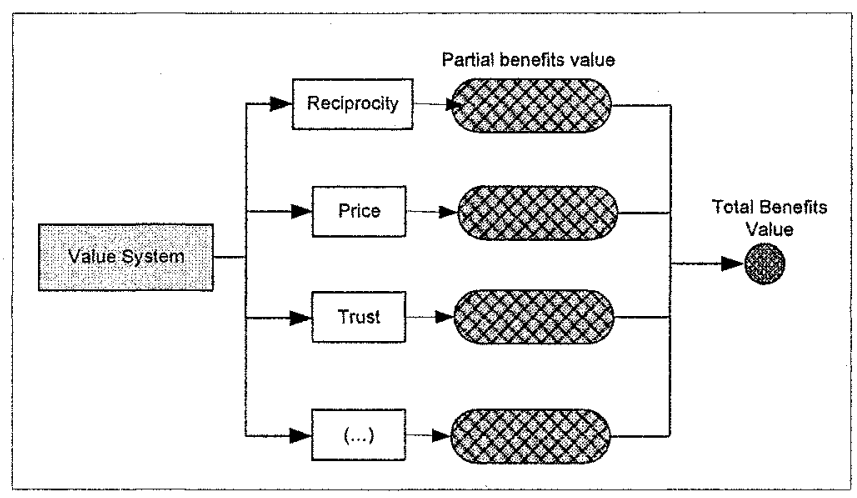

Figure 7 - Example of benefit as a combined abstract value

To illustrate this case, let us consider the following example:

\section{Example 3 - Benefits as a combined abstract value}

An enterprise needs to find a partner in order to accomplish a goal. For that purpose, it announces inside a VBE what its needs are. In order to select a partner, the enterprise builds a specific value system, decides on the relative importance of each variable and defines two reference levels - neutral and good (Fig. 8) and values worse than the neutral level are classified as "bad". Consider now that the enterprise receives bids from three other enterprises E2, E3, and E4, as shown in Fig. 9.

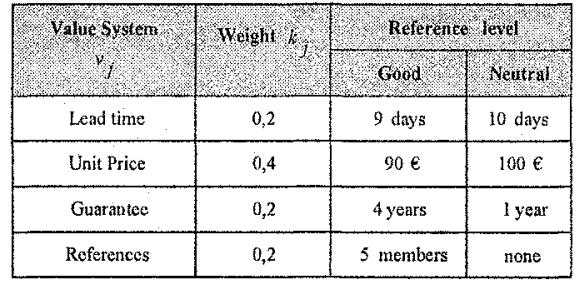

Figure 8 -- Value system and reference level

\begin{tabular}{|l|c|c|c|}
\hline Vilie Systen & L2 & l3 & Ft \\
\hline Lead time & 10 days & 8 days & 8 days \\
\hline Unit Price & $100 €$ & $120 €$ & $80 €$ \\
\hline Guarantee & 5 years & 4 years & 3 years \\
\hline References & 7 members & 6 members & 6 members \\
\hline
\end{tabular}

Figure 9 -Received offers

In order to measure the benefits of each offer, consider that the enterprise applies the following criteria:

$$
V\left(E_{k}\right)=\sum_{j=1}^{n} k_{j} \times v_{j}\left(E_{k}\right) \text { with } \sum_{j=1}^{n} k_{j}=1 \text { e } k_{j}>0 \text { e }\left\{\begin{array}{l}
v_{j}\left(\operatorname{good}_{j}\right)=100 \\
v_{j}\left(\text { neutral }_{j}\right)=0 \\
v_{j}\left(\text { bad }_{j}\right)=-100
\end{array}\right.
$$

Where:

$V\left(E_{k}\right)$ - Total benefits value from the bid of enterprise $E_{k}$

$v_{j}\left(E_{k}\right)$ - Partial benefits value from variable $j$ of the value systems for the bid of enterprise $E_{k}$

$k_{j}$ - Relative importance of variable $j$

As a result, the potential benefit of each offer is given in the table of Fig. 10. 


\begin{tabular}{|c|c|c|c|c|}
\hline 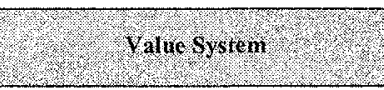 & weight $(x)$ & $v(r)$ & $v\left(P_{r}\right)$ & $\sqrt{\left(F_{4}\right)}$ \\
\hline Lead time & 0,2 & 0 & 20 & 20 \\
\hline Unit Price & 0,4 & 0 & -40 & 40 \\
\hline Guarantee & 0,2 & 20 & 0 & -20 \\
\hline References & 0,2 & 20 & 20 & 20 \\
\hline Cooperation Benefits Value $V\left(E_{k}\right)$ & & 40 & 0 & 60 \\
\hline
\end{tabular}

Figure 10 - Benefit of each offer

Unlike the previous two examples, in this case the concept of benefit is represented as an abstract combined value. Since, the enterprise that contributes with higher benefit value is $\mathrm{E} 4$ on this occasion $\mathrm{E} 4$ will probably be selected.

\section{BENEFITS MODEL}

\subsection{Basic notions}

Let's consider Task Performance Benefits (TB) as the combined benefits that result from the performance of a task in the context of a collaborative process. A collaborative process is understood as a set of tasks performed by the collaborative network members towards the achievement of a common goal (e.g. the business goal that motivates the creation of a Virtual Enterprise).

In this context it is also important to distinguish two set of tasks -dependent and independent. There is a task dependence when the realization of a task by one actor, and therefore the respective benefits, depends on other actors that are not involved in the execution but have an influence on that execution. An example of task dependence occurs when an actor with a good reputation in the market is present as member of a collaborative network and this fact helps others to acquire a contract (task) that otherwise would be lost. This task dependence (or influence from some actors) can be modeled as an enabling factor with a value between 0 (inhibitor) and 1 (enabler) (see, [5] for more details). For all other cases, the tasks are considered independent. For reasons of simplicity we also consider a level of granularity of tasks such that each task is performed by a single member of the network (single actor).

Based on this assumption we define the following set of intuitive concepts:

Self-benefit - benefits for actor $a_{i}$ as a result of performing the task $t_{l}$.

Received benefits - benefits received by actor $a_{i}$ when actor $a_{j}$ performs the task $t_{l}$ (perspective of $a_{i}$ ).

Contributed benefit - benefits from actor $a_{j}$ to actor $a_{i}$ as a result of performing the task $t_{l}$ (perspective of $a_{j}$ ).

In the context of a collaborative network the total self-benefits, received benefits or contributed benefits for a actor $a_{i}$ in a given collaborative process is given by the sum of the benefits obtained from all tasks performed inside of the collaborative network, as shown in table 1 . 
Table 1 - Classes of benefits

\begin{tabular}{|c|c|c|}
\hline Name & Formila & Explanation of variables \\
\hline $\begin{array}{c}\text { Self-benefits } \\
\text { (SB) }\end{array}$ & $\left(S B_{i i}\right)=\sum_{i=1}^{L} T B_{i i}\left(t_{i l}\right)+\sum_{m=1}^{M} D T B_{i i}\left(t_{i m}\right)$ & $\begin{array}{l}T B_{i l} \text { - Task Performance Benefit for actor } a_{i} \\
t_{i l} \text { - Description of a task } t_{l} \text { performed by actor } a_{i} \text {. } \\
D T B_{i i} \text { - Dependable task Benefits for actor } a_{i} \\
\mathrm{~L}-\text { Total } \mathrm{N}^{\mathrm{o}} \text { of independent tasks performed by } a_{i} \text {. } \\
\mathrm{M} \text { - Total of dependent tasks performed by } a_{i}\end{array}$ \\
\hline $\begin{array}{c}\text { Received } \\
\text { Benefits } \\
\text { (RB) }\end{array}$ & $\left(R B_{i j}\right)=\sum_{i=1}^{L} T B_{j i}\left(t_{j l}\right)+\sum_{m=1}^{M} D T B_{j i}\left(t_{j m}\right)$ & $\begin{array}{l}T B_{j i}-\text { Task Performance Benefit from } a_{j} \text { to } a_{i} \\
D T B_{i j} \text { - Dependable task Benefits from actor } a_{j} \text { to } \\
\text { actor } a_{i} \text {. } \\
t_{j l} \text { - Description of a task } t_{l} \text { performed by actor } a_{j} \\
L \text { - Number of tasks performed by actor } a_{j} \\
\mathrm{M} \text { - Total } \mathrm{N}^{\circ} \text { of dependent tasks performed by } a_{j}\end{array}$ \\
\hline $\begin{array}{c}\text { Contributed } \\
\text { Benefits } \\
\text { (CB) }\end{array}$ & $\left(C B_{i j}\right)=\sum_{i=1}^{L} T B_{i j}\left(t_{i l}\right)+\sum_{m=1}^{M} D T B_{i j}\left(t_{i m}\right)$ & $\begin{array}{l}T B_{i j} \text { - Task Performance Benefit from actor } a_{i} \text { to an } \\
\text { actor } a_{j} \text {. } \\
D T B_{i j} \text { - Dependable task Benefits from actor } a_{i} \text { to } \\
\text { actor } a_{j} \text {. } \\
t_{j l} \text { - Description of a task } t_{l} \text { performed by actor } a_{i} \\
L-\text { Number of tasks performed by actor } a_{i} \\
\mathrm{M} \text { - Total } \mathrm{N}^{\circ} \text { of dependent tasks performed by } a_{i} \text {. }\end{array}$ \\
\hline
\end{tabular}

\subsection{Indicators of collaboration}

Table 2 shows a number of basic indicators that can contribute to establish a list of performance indicators tailored to collaborative networks.

Table 2 - Indicators of collaboration

\begin{tabular}{|c|c|c|}
\hline Indlcator & Shor Descrultion & (2) \\
\hline $\begin{array}{c}\text { Social } \\
\text { Contribution } \\
\text { Benefits }\left(\mathbf{S C B}_{i}\right)\end{array}$ & $\begin{array}{l}\text { The sum of benefits contributed by an } \\
\text { actor } a_{i} \text { to all its partners as a result of its } \\
\text { performance in the collaborative process. }\end{array}$ & $\begin{array}{c}S C B_{i}=\sum_{j=1}^{N} C B_{i j} \quad i \neq j \\
\mathrm{~N}-\begin{array}{l}\text { Number of actors involved in } \\
\text { the collaborative process }\end{array}\end{array}$ \\
\hline $\begin{array}{l}\text { External Benefits } \\
\qquad\left(\mathbf{E B}_{\mathrm{i}}\right)\end{array}$ & $\begin{array}{l}\text { The sum of benefits received by an actor } \\
a_{i} \text { as a result of the activity of the other } \\
\text { actors involved in the collaborative } \\
\text { process. }\end{array}$ & $\begin{array}{c}E B_{i}=\sum_{j=1}^{N} R B_{i j} \quad i \neq j \\
\mathrm{~N}-\begin{array}{l}\text { Number of actors involved in } \\
\text { the collaborative process }\end{array}\end{array}$ \\
\hline $\begin{array}{c}\text { Total Individual } \\
\text { Benefits } \\
\left.\text { (TIB }_{\mathrm{i}}\right)\end{array}$ & $\begin{array}{l}\text { The sum of external benefits plus self- } \\
\text { benefits of an actor } a_{i}\end{array}$ & $T I R_{i}=S B_{i}+E B_{i}$ \\
\hline $\begin{array}{c}\text { Individual } \\
\text { Generated } \\
\text { Benefits }\left(\mathbf{I G B}_{\mathbf{i}}\right)\end{array}$ & $\begin{array}{l}\text { The sum of social contributed benefits } \\
\text { plus self-benefits of an actor } a_{i}\end{array}$ & $I G B_{i}=S B_{i}+S C B_{i}$ \\
\hline
\end{tabular}




\begin{tabular}{|c|c|c|}
\hline $\begin{array}{l}\text { Total Received } \\
\text { Benefits } \\
\text { (TRB) }\end{array}$ & $\begin{array}{l}\text { The sum of external benefits achieved by } \\
\text { a set of actors }\end{array}$ & $\begin{array}{c}T R B=\sum_{j=1}^{N} E B_{i} \\
\mathrm{~N}-\begin{array}{c}\text { Number of actors involved in } \\
\text { the collaborative process }\end{array}\end{array}$ \\
\hline $\begin{array}{l}\text { Total Contributed } \\
\text { Benefits } \\
\text { (TCB) }\end{array}$ & $\begin{array}{l}\text { The sum of social contributed benefits } \\
\text { generated by a set of actors }\end{array}$ & $\begin{array}{c}T C B=\sum_{j=1}^{N} S C B_{i} \\
\mathrm{~N}-\begin{array}{c}\text { Number of actors involved in } \\
\text { the collaborative process }\end{array}\end{array}$ \\
\hline $\begin{array}{l}\text { Total Network } \\
\text { Benefits } \\
\text { (TNB) }\end{array}$ & $\begin{array}{l}\text { The sum of benefits achieved by a set of } \\
\text { actors in a specific collaboration process } \\
\text { or over a period of time. }\end{array}$ & $\begin{array}{c}T N B=\sum_{i=1}^{K}\left(S B_{i}+S C B_{i}\right) \\
K-\text { Number of actors involved }\end{array}$ \\
\hline $\begin{array}{c}\text { Progress Ratio } \\
\text { (PR) }\end{array}$ & $\begin{array}{l}\text { This ratio is a macro indicator that } \\
\text { represents the variation of the global } \\
\text { benefits over a period of time. If: } \\
\qquad P R_{\left[t_{1}, x_{2}\right]} \begin{cases}=1 \text { there is no change } \\
>1 \text { TNB increase } \\
<1 T N B \text { decrease }\end{cases} \end{array}$ & $P R_{\left[t_{1}, t_{2}\right]}=\frac{T N B_{2}}{T N B_{1}} \quad t_{2}>t_{1}$ \\
\hline $\begin{array}{l}\text { Social Capital } \\
\text { (SC) }\end{array}$ & $\begin{array}{l}\text { Social capital can be defined as the sum } \\
\text { of resources, that accrue to an individual } \\
\text { or a group by virtue of possessing a } \\
\text { durable network of more or less } \\
\text { institutionalized relationships of mutual } \\
\text { acquaintance and recognition [2]. In the } \\
\text { context of a collaborative network, SC } \\
\text { can be seen as the density of the network } \\
\text { benefits relation. }\end{array}$ & $\begin{array}{c}S C=\frac{2 R}{K \times(K-1)} \\
R-\text { Number of collaborative } \\
\text { relations in the network } \\
K-\text { Number of actors involved }\end{array}$ \\
\hline $\begin{array}{l}\text { Cooperative } \\
\text { Development } \\
\text { Ratio } \\
\text { (CDR) }\end{array}$ & $\begin{array}{l}\text { The aim of this ratio is to measure the } \\
\text { progress of collaborative benefits for a set } \\
\text { of actors over a period of time. If: } \\
C D R_{\left[4_{1}, c_{2}\right]}\left\{\begin{array}{l}=1 \text { there is no change } \\
>1 \text { cooperation benefits increase } \\
<1 \text { cooperation beneits decrease }\end{array}\right.\end{array}$ & $C D R_{\left[b_{1}, r_{2}\right]}=\frac{\left(\sum_{i=1}^{N} S C B_{i}\right)_{2}}{\left(\sum_{i=1}^{N} S C B_{i}\right)_{1}}$ \\
\hline $\begin{array}{l}\text { Individual } \\
\text { contribution } \\
\text { index } \\
\left(\mathrm{ICI}_{\mathbf{1}}\right)\end{array}$ & $\begin{array}{l}\text { Normalized contribution of an actor } a_{i} \text { to } \\
\text { the collaborative network }\end{array}$ & $\begin{array}{c}I C I_{i}=\frac{S C B_{i}}{\sum_{j=1}^{N} S C B_{i}} \\
\mathrm{~N}-\begin{array}{c}\text { Number of actors involved in } \\
\text { the collaborative process }\end{array}\end{array}$ \\
\hline $\begin{array}{c}\text { Apparent } \\
\text { individual } \\
\text { contribution } \\
\text { index } \\
\left(\mathbf{A C I}_{\mathbf{i}}\right)\end{array}$ & $\begin{array}{l}\text { An indicator based on the number of } \\
\text { contribution links (i.e. the out degree of } \\
\text { the actor in the graph representing the } \\
\text { collaboration benefits). This index gives } \\
\text { an apparent and simple to compute } \\
\text { measure of the involvement of an actor as } \\
\text { a contributor to the collaboration process. } \\
\text { An actor with an ACI close to zero is not } \\
\text { perceived as a good contributor to the } \\
\text { network (although the real value of its } \\
\text { contribution is better expressed by ICI). }\end{array}$ & $\begin{array}{c}A C I_{i}=\frac{N^{\circ} \text { out links leaving } a_{i}}{N-1} \\
\mathrm{~N}-\begin{array}{l}\text { Number of actors involved in } \\
\text { the collaborative process }\end{array}\end{array}$ \\
\hline $\begin{array}{l}\text { Individual } \\
\text { external benefits } \\
\text { index } \\
\left(\mathbf{I B I}_{\mathrm{i}}\right)\end{array}$ & $\begin{array}{l}\text { Normalized external benefits received by } \\
\text { an actor. } \\
\text { This index expresses the popularity or } \\
\text { prestige of the actor [12] in the sense that } \\
\text { actors that are prestigious tend to receive } \\
\text { many external benefits links. }\end{array}$ & $\begin{array}{c}\qquad I B I_{i}=\frac{E B_{i}}{\sum_{j=1}^{N} E B_{i}} \\
\mathrm{~N}-\begin{array}{l}\text { Number of actors involved in } \\
\text { the collaborative process }\end{array}\end{array}$ \\
\hline
\end{tabular}




\begin{tabular}{|c|c|c|}
\hline $\begin{array}{c}\text { Apparent } \\
\text { individual } \\
\text { benefits index } \\
\left.(\mathbf{A B I})_{i}\right)\end{array}$ & $\begin{array}{l}\text { An indicator based on the number of } \\
\text { received contribution links (i.e. the in } \\
\text { degree of the actor in the graph } \\
\text { representing the collaboration benefits). } \\
\text { Similarly to IBI, this index also expresses } \\
\text { the popularity or prestige of the actor. }\end{array}$ & $\begin{array}{c}A B I_{i}=\frac{N^{0} \text { links arriving at } a_{i}}{N-1} \\
\mathrm{~N}-\begin{array}{l}\text { Number of actors involved in } \\
\text { the collaborative process }\end{array}\end{array}$ \\
\hline $\begin{array}{l}\text { Reciprocity index } \\
\text { (RI) }\end{array}$ & $\begin{array}{l}\text { The balance between benefits credit (the } \\
\text { sum of benefits contributed by an actor } \\
a_{i} \text { to all its partners (or one specific } \\
\text { partner)) and benefits debit (the sum of } \\
\text { benefits received by an actor } a_{i} \text { as a } \\
\text { result of the performance of all actors (or } \\
\text { one specific partner) involved in the } \\
\text { collaborative process). If: } \\
\qquad R I\left\{\begin{array}{l}<0 \text { selfish behavior } \\
=0 \text { null balance } \\
>0 \text { altruistic behavior }\end{array}\right.\end{array}$ & $\begin{array}{l}\mathrm{N}-\mathrm{Number} \text { of actors involved in } \\
\text { the collaborative process }\end{array}$ \\
\hline
\end{tabular}

\section{POTENTIAL APPLICATION IN VBE CONTEXT}

Let us suppose we keep a record of the past collaborative processes where the benefits values are stored. Using simple calculations as illustrated in table 2, and some simple statistics, it is possible to extract several macro and micro indicators regarding the performance of the VBE and its members as a collaborative structure. These indicators can be determined for a particular collaboration process (a particular VO occurrence) or over a period of time (average values for the VBE) and can be used in decision-making processes, such as planning a new VO. For instance:

At the VBE management level: Global indicators (e.g. total network benefits - TNB, progress ratio - PR, social capital - SC, development cooperative ratio - DCR) or member specific indicators (e.g. reciprocity index - RI, Social Contribution index SCB, Apparent individual benefit index - ABI, Apparent individual contribution index - ACI ).

At the broker's level: Indicators that may help in partner selection for a specific VO (e.g. individual contribution index - ICI). For partners selection it is also important to analyze the history of dyads, an actor $a_{i}$ might be more effective when collaborating with a specific actor $a_{j}$ than with any other in the VBE, (reciprocity index - RI). For the analysis of the VO (e.g. total network benefits - TNB, total contributed benefits - TCB or total received benefits - TRB of the VO, etc.). For instance, if the benefits in a particular VO are mainly self-benefits it means the level of (explicit) collaboration is low (the work could be done in isolation).

At the member's level: Indicators that may help a member find answers for questions such as: Shall I get involved in this consortium? (e.g. Individual Generated Benefits - IGB); Was my participation in this collaborative process beneficial to me? (e. g. external benefits - EB, total individual benefits - TIB); What is my level of "popularity" or "prestige"? (e.g. individual external benefits index - IBI) What is the balance of my interactions with a specific member (dyad relationship)? Have I got reciprocity, in the past, from the potential members to be involved in the same VO? (e.g. reciprocity index - RI). 
The main difficulty is naturally the determination of the benefits corresponding to each collaborative task/process. To collect and record those values without being intrusive in the network members "life" requires further research and development.

\section{CONCLUSIONS}

The characterization and understanding of collaboration benefits is a key precondition for a wide adoption of the collaborative networks paradigm in its various manifestation forms. This understanding is also a base for the establishment of proper performance indicators to be used in decision making processes at various levels: VO breeding environment management, VO brokering, and VO breeding environment membership. Some preliminary steps in this direction, inspired in the Social Networks analysis but also taking some insights from other areas such as transaction costs and game theories, were presented. Initial results illustrate the applicability of the suggested approach. The development of full practical framework for performance measurement and benefits analysis in collaborative networks still requires further work.

Acknowledgments - This work as supported in part by the ECOLEAD integrated project funded by the European Commission.

\section{REFERENCES}

1. Axelroad, R. (1984). The Evolution of Cooperation, Basic Books.

2. Bourdieu, P.; L. Wacquant, (1992). An invitation to reflexive sociology, Chicago: University of Chicago Press.

3. Borgatti, S.P., Everett, M.G. and Freeman, L.C. 2002. Ucinet for Windows: Software for Social Network Analysis. Harvard, MA: Analytic Technologies.

4. Camarinha-Matos, L. M.; Abreu, António (2004). A contribution to understand collaborative benefits - Emerging solutions for future manufacturing systems, Springer, ISBN 0-387-22828-4.

5. Camarinha-Matos, L. M.; Afsarmanesh, H. (2003). Elements of a VE base infrastructure, J. Computers in Industry, Vol. 51, Issue 2, Jun 2003, pp. 139-163.

6. Camarinha-Matos, L. M.; Afsarmanesh, H. (Ed.s) (2004). Collaborative Networked Organizations - A research agenda for emerging business models, Kluwer Academic Publishers, ISBN 1-4020-7823-4.

7. Evans, S.; Roth, N.; Sturm, F. (2004). Performance measurement and added value of networks, in Collaborative Networked Organizations - A research agenda for emerging business models, Kluwer Academic Publishers, ISBN 1-4020-7823-4.

8. Kolakovic, Marko (2003).VAVE - A model for measuring the business performance of virtual enterprise - Business Excellence I, performance measures, benchmarking and best practices in new economy, University of Minho, ISBN 972-8692-08-0.

9. Myerson, R. B. (1997). Game Theory Analysis of Conflict, Harvard University Press.

10. Seifert, Marcus; Eschenbaecher, Jens (2004). Predictive performance measurement in virtual organisations - Emerging solutions for future manufacturing systems, Springer, ISBN 0-387-22828-4.

11. Vallejos, Rolando Vargas; Gomes, Jefferson de Oliveira (2004). Applying a benchmarking methodology to empower a virtual organisation - Emerging solutions for future manufacturing systems, Springer, ISBN 0-387-22828-4.

12. Wasserman, S. and K. Faust. (1994). Social Network Analysis - Methods and Applications. Cambridge University press.

13. Williamson, O. E. (1985). The Economic Institutions of Capitalism: Firms, Markets, Relational Contracting, New York: Free Press. 